\title{
Mindful Teaching: A Narrative Exploration of Mindfulness
}

\author{
Dhevy Puswiartika \\ Faculty of Teacher Training and Education \\ Tadulako University \\ Palu, Indonesia \\ dhevyprodibk@gmail.com
}

\author{
Marina Sulastiana \\ Faculty of Psychology \\ Padjadjaran University \\ Sumedang, Indonesia
}

\author{
Zahrotur Rusyida Hinduan \\ Faculty of Psychology \\ Padjadjaran University \\ Sumedang, Indonesia
}

\author{
Diana Harding \\ Faculty of Psychology \\ Padjadjaran University \\ Sumedang, Indonesia
}

\begin{abstract}
Mindfulness will refer to intentionally paying attention to the here and now experience without judgment. Mindfulness has shown promise as an intervention to be used for a broad range of ages and presenting concerns. It has very recently begun to be explored as an effective way to enhance the services provided by various caregiver professions, in ways that seemed to have clear implications for teachers. The previous study found that classroom teachers believed mindfulness to have been helpful in their personal and professional lives. This study explored how teachers related mindfulness to their livelihoods. This research was using qualitative methodology with semi-structured observation and in-depth interview method. The results described that participants found mindfulness to be useful in their personal and professional lives and thought that their own mindfulness practice was helpful to teach their students. Recommendations include offering courses on mindfulness to teachers, bringing mindfulness to all school personnel at schools, and integrating mindfulness into existing teacher preparation programs.
\end{abstract}

\section{Keywords- mindfulness; teaching; intervention; narrative; exploration}

\section{INTRODUCTION}

The origin of the concept of mindfulness lies in Eastern religions such as Hinduism and Buddhism. In these traditions, mindfulness refers to a complete awareness of the body functions, feelings, thoughts and consciousness itself. This current conceptualization is based on Jon Kabat Zinn's western approach to Buddhism and has been adopted by most who formally study the topic. His definition states that mindfulness means "paying attention in a particular way: on purpose, in the present moment, and non-judgmentally" [6].

Mindfulness has also been described as a state of consciousness or state [4]; [8]. However, even with this conceptual framework for mindfulness, it is understood that individuals may employ this state of consciousness with differing levels of frequency and that there are varying levels of mindfulness within these states [1]. Many researchers have postulated that it is possible to increase employment of mindful states and that increasing mindfulness can be beneficial for individuals with and without psychological disorders [5]; [9]. In this context, mindfulness is used to enhance clients' abilities to experience their emotions fully and without judgment [2]

Mindfulness had been shown to be effective for a variety of other caregiving relationships in ways that seemed to have clear implications for teachers [11]. There were already a few training programs that brought mindfulness to teachers. Mindfulness training for teachers found positive results in reducing anxiety, depression, and stress [14].

\section{A. Benefit of Mindfulness}

Mindfulness-based stress reduction had positive physical, emotional, mental, spiritual, and interpersonal effects [14]. Most participants had intentions to integrate mindfulness into their future professions. The evidence, therefore, suggests that caregivers have benefited from mindfulness training in a variety of ways that could, also, translate into better care received [10].

Finally, mindfulness-based cognitive therapy is a more recent hybrid of mindfulness meditation and more traditional mental health treatment and has been shown to be effective in reducing recurrent suicidality [15], treating recurrent depression in the elderly [12], reducing residual depressive symptoms (especially rumination) [7], and preventing relapse in individuals with recurring depression (3 or more previous 
periods of depression) [13]. The mindfulness-based cognitive therapy combines mindfulness and traditional cognitivebehavioral therapy by using mindfulness to increase acceptance of thoughts and emotions [3] so that they can be experienced fully and then let go, instead of labeling them as inaccurate or pathological as in the more traditional treatment [13].

\section{B. Mindfulness for Teachers}

One caregiving profession that has received less attention in the mindfulness literature is teaching. One contemporary study regarding mindfulness training for teachers [14] engaged the investigators, who conducted mindfulness-based stress reduction with self-selected elementary school teachers. Pre and post measures indicated that some aspects of anxiety, depression, and stress (according to published and standardized self-report measures). The program also made a statistically significant impact on some aspects of mindfulness approaches with teachers to improve well-being and increase mindfulness.

An earlier study by [14] brings some qualitative data to bear on the subject of mindfulness for classroom teachers. Interviews were conducted with two teachers who have a mindfulness practice: one experienced teacher/mediator and one relatively new to both teaching and meditation. A thematic analysis was conducted and validity was established through peer debriefing and member checking. Themes identified included: teaching is stressful, mindfulness is helpful for teachers, mindfulness is beneficial for students, mindfulness training should begin with teachers who can then teach it to students, mindful teaching benefits the classroom environment and teacher-student relationships, there are obstacles to teachers learning mindfulness, links between mindfulness and other important concepts exist, mindfulness can be used while teaching, and daily mindfulness practice is important.

\section{METHODS}

This research was using qualitative methodology. A qualitative method was the procedure of the research that produced a description as a word was written and verbal analysis from the subjects on the research. This approach refers to the individual background as holistic. The participants in this study included 3 people who are currently working as teachers on inclusion primary school in Jakarta and have classroom teaching experience in the recent past. Three participants were female and one was male. All were experienced educators with a minimum of 5 years of experience with classroom teaching. The data had been collected by having a semi-structured observation and in-depth interview method. In this research, the researcher act as the main research instrument within collecting data. The data analysis on this research had done by performing thematic analysis [14]. The thematic analysis draws out themes across interviews and participants.

\section{RESULT AND DISCUSSION}

The research question that guided this study was "What insights about mindfulness and teaching can be articulated by understanding how mindfulness practitioners perceive/conceptualize the link between their mindfulness practices and their teaching livelihood?"

Subject $\mathrm{F}$ has been teaching for 12 years and currently teaches inclusion primary school on math subject for grade 6 . She started mindfulness practice through attending a course on mindfulness after encouragement from a friend who is also a teacher and later sought ways to teach mindfulness to students. She told stories of directly teaching mindfulness to students both individually and in groups. She also mentioned seeing the value of her own mindfulness practice for students in terms of modeling what she had found to be a helpful practice. F also found mindfulness beneficial to herself as a teacher in that it helped her to avoid the common teacher practice of yelling at students, which she found to be unskillful. F also often spoke of mindfulness as consisting of taking deep breaths. In other words, taking deep breaths can help one to center and focus in order to be more mindful and mindfulness can help one to remember to take deep breaths to calm down.

This is also an example of $F$ measuring her effectiveness as a teacher and mindfulness' effectiveness for students by her ability to control students' behavior involved:

"And it really helped me so much. I will always remember that I'm gonna try something, it's called mindfulness - we can't use the word meditation. On that time I was feeling really really mad when I got to class on the morning. And I was thinking, of course, I noticed my body seemed very angry. And then -I take deep breaths and I feel a lot better. I think we could do that as a class. I think it'd be a good thing. I don't know. It worked."

This excerpt tells how $\mathrm{F}$ relates mindfulness to taking deep breathing and how she considers this to be helpful to herself as a teacher in a number of ways. In this excerpt we finally see F's desire to connect with both her own experience and with her students:

"Well, when someone's doing something incorrectly, a lot of times I like to take a deep breath or a couple deep breaths. And when I do that, it makes it so that - I can then focus on what I should do to solve the problem, it's not an in the moment reaction. And I think I'm more patient, and I'm more focused on thinking about someone else's perspective when I take some deep breaths before responding. I don't do it all the time, even though that's my intention. But it does help a lot, especially with certain students."

Subject DR has been teaching for 15 years and currently teaches inclusion primary school on science subject for grade 6. DR sought out mindfulness out of a desire to help her students on concentration problem. She told a story about realizing that she is always rushing through things and then mentioned several situations with students in which she realized she was not taking enough time to allow things to 
unfold. DR seemed to be authentically using mindfulness to feel into these encounters and then to change her own behavior accordingly. DR talking about how mindfulness brings awareness to one's own problematic behaviors so that one can then choose to change and also spoke of how mindfulness is not about being calm but is instead about being fully aware of what is happening and feeling into one's experience. She also told stories of using mindfulness in challenging communications with both coworkers and students' parents. In each of these cases, she seemed to be highly reflective regarding her own contributions to these challenges and what it felt like in these difficult encounters. Overall, DR seemed very willing to use mindfulness to bring awareness to her own faults both personally and professionally and to make changes based on what she found. She seemed to conceptualize mindfulness primarily in terms of heightened awareness of what is happening in the moment both internally and externally. DR uses taking a couple breaths to give herself space in which she can determine why she is upset with students and do self-regulation.

There was the depth of DR'sunderstanding of mindfulness on this excerpt:

"I am thinking back, looking into mindfulness and then realizing I started doing some of that for that kind of reason but I understood what mindfulness was and it's not really about calming, it's about just being with the present and it just really resonated with me. So that also informs my practice and my teaching, that those students, today, they had a hard time settling down. That everybody has, on any given day, last week might have been great, and settle down right away, and next week, maybe not so much. And I think for me it brings a lot more compassion and understands, especially for me as a type. I think the biggest thing that changed was my language with the kids, that changed their behavior and stuff. And so I think mindfulness helped a lot with that about being aware and picking up on that and it's much better now but it's definitely something that I'm working on."

$\mathrm{S}$ has been teaching for 8 years and currently teaches inclusion primary school on Indonesian subject for grade 6 . He came into mindfulness as he was going through a difficult time and found inspiration in a book about mindfulness. He was in and out of the practice for some time before another life challenge brought him back to the book and deepened his understanding and experience of the practice greatly. S also talked about how his own mindfulness practice is helpful to his students because of the difference in his presence whether or not he teaches mindfulness to them directly. S described clearly shift in presence as well its relationship with having an open heart and building connections with students. S demonstrated mindfulness with these descriptions as they tapped into the felt experiences of mindfulness and openheartedness respectively. S primarily conceptualized mindfulness in terms of being fully present with here and now felt the experience. Like both $\mathrm{F}$ and DR, S spoke about realizing that offering mindfulness practices to students was helpful and well received.

This excerpt also demonstrates $\mathrm{S}$ valuing of students' autonomy and the resulting increase in their engagement in mindfulness:

" I think that's kind of where I stand on it too, just, let's see if they feel the difference, and even if there are some that are going to be unwilling to do it just like there were some who, even when doing a mindful minute, found it funny to laugh out loud or talk or purposefully do things. But those same students, the second or the third or the fourth time...they tried a little harder and there was no reward given, I think it was just more the, yeah just the seeing other people actually and noticing that there is a different sort of energy when you're doing mindfulness. It's just a matter of learning to be patient and when it, if it, if I keep, continue and persistent in finding trainings and making it a part of my life then eventually, I mean no matter what even without implementing any mindful lesson in school, even without that I really do believe that the ways that it's benefited me, it is why I can be the way I am in the classroom. And it makes me a better teacher no matter what. It's changed my life in a hundred different ways. It was like, wow I really need to change a lot of my lifestyle."

The results described that participants found mindfulness to be useful in their personal and professional lives and thought that their own mindfulness practice was helpful to teach their students.

\section{CONCLUSION}

The conclusion of the study, the mindfulness practice had a positive effect on teaching. Recommendations include offering courses on mindfulness to teachers, bringing mindfulness to all school personnel at schools, and integrating mindfulness into existing teacher preparation programs.

\section{REFERENCES}

[1] R. A. Baer. "Mindfulness training as a clinical intervention: A conceptual and empirical review". Clinical Psychology: Science and Practice, 10, 125-143, 2003.

[2] S.R.Bishop,M Lau,S. Shapiro, L. Carlson, N.D. Anderson, J. Carmody, Z.V. Segal, S. Abbey, M. Speca, \& D. Velting. "Mindfulness: A proposed operational definition". Clinical Psychology: Science and Practice, 11: 230-241, 2004

[3] D.A. Black. Mindfulness Research Guide (MRG). Retrieved from www.mindfulexperience.org., 2015.

[4] K.W. Brown, R.M. Ryan, \&J.D. Creswell, "Mindfulness: Theoretical foundations and evidence for its salutary effects." Psychological Inquiry, 18: 211-237., 2007

[5] K.W. Brown, R.M. Ryan, \& J.D. Creswell, Handbook of Mindfulness: Theory, Research, and Practice. New York: The Guilford Press., 2015.

[6] J. Kabat-Zinn. "Mindfulness-based interventions in context: Past, present, and future', Clinical Psychology Science and Practice, 10: 144156, 2003.

[7] T. Kingston, B. Dooley, A. Bates, E. Lawlor, E, \& K. Malone "Mindfulness-based cognitive therapy for residual depressive symptoms", Psychology \& Psychotherapy: Theory, Research \& Practice, 80(2), 193-203, 2007. 
[8] E.J. Langer, Mindfulness. Reading, MA: Addison-Wesley, 1989.

[9] M.A.Lau\& S.F. McMain, "Integrating mindfulness meditation with cognitive and behavioral therapies: The challenge of combining acceptance-and change-based strategies", Canadian Journal of Psychiatry, 50(13), 863-869, 2005.

[10] Z. Segal, J. Williams, \& J. Teasdale. Mindfulness-based cognitive therapy for depression: A new approach to preventing relapse. New York: Guilford Press, 2002.

[11] S, Shapiro \& C. White, Mindful Discipline: A loving approach to setting limits and raising an emotionally intelligent child. Oakland, CA: New Harbinger Publications, Inc, 2014
[12] A. Smith, L. Graham,\&S. Senthinathan, "Mindfulness-based cognitive therapy for recurring depression in older people: A qualitative study", Aging \& Mental Health, 11(3),346-357, 2007.

[13] J.D. Teasdale, "Metacognition, mindfulness and the modification of mood disorders", Clinical Psychology \& Psychotherapy,6(2), 146-155, 1999.

[14] K. Thomas, Mindful Teaching. Dissertation. USA: Indiana University, 2015.

[15] J.M.G. Williams, D.S. Duggan, C. Crane, \&M.J.V. Fennell, "Mindfulness-based cognitive therapy for prevention of recurrence of suicidal behavior",Journal of Clinical Psychology, 62(2), 201-210, 2006. 